\title{
Looking Back, Looking Forward
}

\author{
James J. James, MD, DrPh, MHA
}

A $\mathrm{t}$ the time we prepared the editorial "Fearbola" for the December issue of the journal, ${ }^{1}$ there had been 15,352 cases of Ebola "officially" reported, with 5790 cumulative deaths (38\% mortality) resulting from the West African epidemic. Now as of January 13, there have been a total of 21,408 cases with 8483 deaths (39.6\% mortality) reported. These numbers obviously indicate that this epidemic is far from over, although the epidemiologic curves indicate a significant decrease in monthly new cases, especially in Guinea and Liberia but with a lesser positive effect for Sierra Leone. Overall, the belated but massive worldwide response to the situation is having a positive albeit slow effect on controlling and ultimately abating the epidemic.

Several months ago as the true severity of the epidemic and its global implications became apparent, we at the journal launched a novel concept for a peer-reviewed journal in which we defined an e-issue online and began to collect commentaries and articles from responders, managers, academics, and policy makers actually involved with the global response. All materials were peer reviewed and published online as expeditiously as possible. The stated intent was to provide information, data, and observations on the course of the epidemic; the effect on medical and public health interventions; and lessons learned to assist in the response and not simply as a retrospective description or analysis of events. Additionally, it was hoped that a historical record would result as the intent was to collect papers over the full course of the event.

Because of the volume of materials received, we have decided to publish the Ebola special issue collection in sections. We are most proud to introduce Section 1 in this, the February issue of 2015. When all future sections are published we will attempt to identify a sponsor or sponsors to enable us to publish a separate supplement to the journal. We are excited by the results of this project and intend to follow this process in the future for major events. From a general perspective, the impact of the Ebola issue has been extremely positive. This is dramatically demonstrated in Table 1, which shows online views of journal content. Among the most-viewed articles of the journal, 9 of these publications represent articles submitted for the Ebola special issue, with "A Primer

\begin{tabular}{|c|c|c|c|c|}
\hline \multicolumn{5}{|c|}{ Online Views of Journal Content in 2014} \\
\hline Month & $\begin{array}{l}\text { Abstract } \\
\text { Views }\end{array}$ & $\begin{array}{c}\text { Table of Contents } \\
\text { Views }\end{array}$ & $\begin{array}{c}\text { Full Text } \\
\text { Views }\end{array}$ & $\begin{array}{l}\text { PDF } \\
\text { views }\end{array}$ \\
\hline January & 5460 & 3155 & 1152 & 1113 \\
\hline February & 5547 & 3763 & 1168 & 1131 \\
\hline March & 8772 & 3996 & 1852 & 1790 \\
\hline April & 9724 & 3323 & 2674 & 2650 \\
\hline May & 9561 & 3160 & 1770 & 1726 \\
\hline June & 9366 & 3078 & 1854 & 1816 \\
\hline July & 12,058 & 3698 & 1639 & 1540 \\
\hline August & 11,438 & 6651 & 1681 & 1592 \\
\hline September & 12,797 & 8802 & 2139 & 2036 \\
\hline October & 25,771 & 8872 & 7191 & 5449 \\
\hline November & 17,544 & 9831 & 4497 & 3789 \\
\hline December & 12,567 & 8972 & 3042 & 2774 \\
\hline Totals & 140,605 & 67,301 & 30,659 & 27,406 \\
\hline
\end{tabular}

on Ebola for Clinicians" ${ }^{2}$ being the most accessed article in the journal's history.

Of course, every success comes at some cost, and for the journal as a whole, that is reflected in the dramatic increase in overall submissions, which went from 96 in 2013 to 240 in 2014. This has led to an increase in workload for a limited number of Associate Editors and increasing times to publication for authors. To address this, we will be moving to a Section Editor model under which we will have 12 or more defined sections that remain to be identified. We will be aggressively pursuing this approach and will be asking you the reader for help in identifying section types and qualified individuals to fill the Section Editor positions. There will be much to follow on this in future publications as well as discussion of such important topics as special and supplemental issues. In closing, I simply thank all of you out there for the work and support given in the past and look forward to our future together.

\section{REFERENCES}

1. James JJ. Fearbola. Disaster Med Public Health Prep. 2014;8:465-466. doi:10.1017/dmp.2014.155

2. Toner E, Adalja A, Inglesby T. A primer on Ebola for clinicians [published online ahead of print October 17, 2014]. Disaster Med Public Health Prep. doi:10.1017/dmp.2014.115 